\title{
ANALISIS DATA SEBARAN BANDWIDTH MENGGUNAKAN ALGORITMA DBSCAN UNTUK MENENTUKAN TINGKAT KEBUTUHAN BANDWIDTH DI KABUPATEN PURWAKARTA
}

\author{
1) Teguh Iman Hermanto, ${ }^{2)}$ Yusuf Muhyidin \\ ${ }^{1,2)}$ Teknik Informatika, STT Wastukancana Purwakarta \\ 1,2) J1. Cikopak No. 53, Sadang, Purwakarta - Jawa Barat - Indonesia \\ E-mail :teguh@stt-wastukancana.ac.id
}

\begin{abstract}
ABSTRAK
Berdasarkan data yang tercatat pada tahun 2018 terdapat 43 organisasi perangkat daerah di kabupaten Purwakarta yang sudah mendapatkan bandwidth internet. Namun saat ini jumlah pembagian bandwidth dan tingkat kebutuhan belum dapat dikelompokan. Tujuan dari penelitian ini untuk menetukan tingkat kebutuhan bandwidth di Purwakarta dengan cara melakukan analisis data mining terhadap data yang ada menggunakan algoritma DBSCAN sehingga akan terbentuk cluster yang yang dibagi berdasarkan tingkat kebutuhan. Pada penelitian ini metode analisis yang digunakan yaitu SEMMA dengan tahapan meliputi Data Selection, Pre-processing / cleaning, Transformation, Data Mining dan Assess / Evaluation. Hasil dari analisis menggunakan nilai minpts $=5$ dan nilai epsilon $=3$. Cluster yang terbentuk yaitu sebanyak 2 cluster, cluster 1 merupakan tingkat kebutuhan bandwidth rendah dan cluster 2 merupakan tingkat kebutuhan bandwidth sedang, dan 1 Noise merupaapakan tingat kebutuhan bandwidth yang terlalu tinggi. Dari hasil cluster yang terbentuk dapat digunakan untuk pemerataan kebutuhan bandwidth pada organisasi perangkat daerah di kabupaten Purwakarta.
\end{abstract}

Kata Kunci: analisis, Data Mining, SEMMA, DBSCAN.

\section{ABSTRACT}

Based on data recorded in 2018 there are 43 regional apparatus organizations in Purwakarta regency that have gained internet bandwidth. However, at this time the amount of bandwidth sharing and the level of needs cannot be grouped yet. The purpose of this study is to determine the level of bandwidth requirements in Purwakarta by analyzing data mining of existing data using the DBSCAN algorithm so that a cluster will be formed which is divided based on the level of need. In this study the analytical method used is SEMMA with stages including Data Selection, Pre-processing / cleaning, Transformation, Data Mining and Assess / Evaluation. The results of the analysis use the value of minpts $=5$ and epsilon value $=3$. The clusters formed are as many as 2 clusters, cluster 1 is the level of low bandwidth requirements and cluster 2 is the level of medium bandwidth requirements, and 1 Noise is a reminder that bandwidth requirements are too high. From the results of the cluster formed can be used to equalize the bandwidth requirements of regional device organizations in Purwakarta district.

Keyword: Analysis, Data Mining, SEMMA, DBSCAN.

\section{PENDAHULUAN}

Dinas Komunikasi dan Informatika (Diskominfo) Kabupaten Purwakarta, terdiri dari 4 (empat) bidang yaitu Bidang Aplikasi dan Informatika (Aptika), Bidang Teknologi Informasi (Jaringan), Bidang Statistik dan Persandian dan Bidang Informasi dan Komunikasi Publik. Dinas Komunikasi dan Informatika Kabupaten Purwakarta merupakan salah satu instansi pemerintah yang mempunyai tugas membantu Bupati melaksanakan urusan pemerintahan bidang komunikasi dan informatika, bidang persandian, dan bidang statistik yang menjadi kewenangan Kecamatan dan tugas pembantuan yang ditugaskan kepada Kecamatan.

Berdasarkan data yang tercatat hingga saat ini terdapat 43 sebaran bandwidth internet di kabupaten Purwakarta yang tersebar di setiap organisasi perangkat daerah. Jumlah ini diambil dari data sebaran bandwidth internet tahun 2018 dan belum termasuk organisasi perangkat daerah yang belum mendapatkan akses untuk bandwidth internet. Untuk pertambahan kecepatan 
maupun bandwidth internet itu disesuaikan dengan anggaran yang ada di Dinas Komunikasi dan Informatika.

Dalam penelitian ini penulis melakukan proses Clustering dilakukan dengan menggunakan metode Density Based Spatial Clustering of Application With Noise. Density Based Spatial Clustering of Application With Noise merupakan metode yang dikembangkan berdasarkan density (kepadatan) tertentu. Metode ini menganggap cluster sebagai suatu area yang berisi objek-objek yang padat atau sesak, yang dipisahkan oleh area yang memiliki kepadatan rendah (merepresentasikan Noise).

Density Based Spatial Clustering of Application With Noise adalah algoritma menumbuhkan area-area dengan kepadatan yang cukup tinggi ke dalam cluster-cluster and menemukan cluster-cluster dalam bentuk yang sembarang dalam suatu database spatial yang memuat Noise [1].

Data mining merupakan suatu konsep yang umumnya digunakan untuk menemukan pengetahuan yang tersembunyi dalam basis data [2]. Data mining dibagi menjadi beberapa kelompok berdasarkan tugas yang dapat di lakukan yaitu Deskripsi, Estimasi, Prediksi, Klasifikasi, Pengklasteran, dan Asosiasi [3].

SEMMA merupakan singkatan dari Sample, Explore, Modify, Model, Assess. Singkatan tersebut mengacu pada proses dalam melakkan sebuah objek data mining. Pada umunya penerapanya, SAS institute membagi siklus SEMMA menjadi 5(lima) tahapan untuk proses data mining [4].

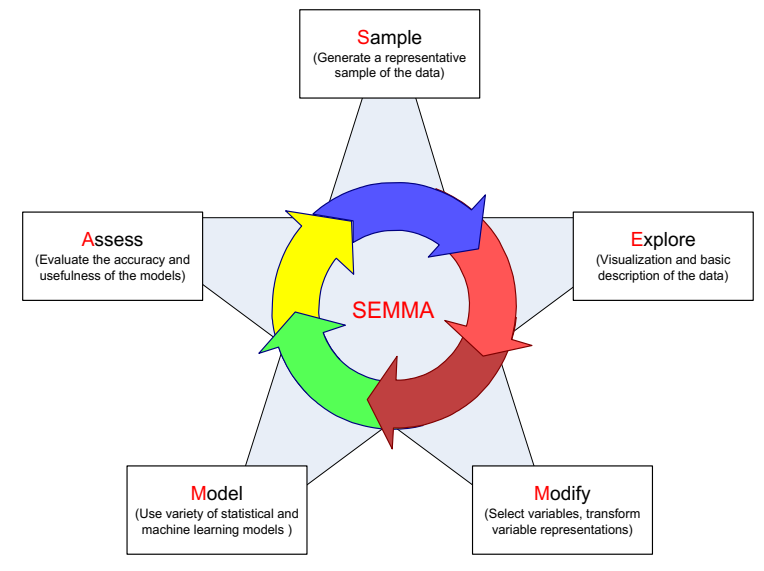

Gambar 1. Tahapan dalam SEMMA

\section{METODE}

Pada penelitian ini penulis menggunakan metode SEMMA dalam pengolahan data menggunakan Teknik data mining sebagai berikut (a) Tahap pengumpulan data (Sample), (b) Tahap deskripsi data (Explore), (c) Tahap transformasi data (Modify), (d) Tahap pemodelan data (Model), (e) Tahap evaluasi data (Asses) [5] :

a. Tahap Pengumpulan data (Sample)

Pada tahap ini Penulis mengumpulkan data dengan meminta data sebaran Bandwidth yang berjumlah 43 organisasi perangkat daerah Purwakarta.

b. Tahap deskripsi data (Explore)

Dari data yang terkumpul, dilakukan pengeksplorasian dengan menjelaskan data secara lengkap mulai dari data nama perangkat daerah sesuai dengan atributatribut seperti koordinat latitude, koordinat longitude, sebaran bandwidth, kapasitas metro, dan jumlah pengguna. Pada tahap ini juga dilakukan Data Selection dan Data Pre-processing/ Data Cleaning.

c. Tahap transformasi data (Modify)

Tahap ini melakukan modifikasi terhadap data dengan menciptakan, memilih, dan mengubah variable untuk focus pada proses pemilihan model. 
d. Tahap pemodelan data (Model)

Tahap ini terdiri dari pemodelan data dengan suatu perangkat lunak untuk mencari kombinasi data yang dapat memprediksi hasil yang diinginkan.

e. Tahap evaluasi data (Asses)

Tahap ini terdiri dari penilaian data dengan mengevaluasi kegunaan dan keandalan dari temuan pada proses data mining
HASIL

\section{A. Sample}

Sumber data utama yang digunakan dalam penelitian ini berasal dari data sebaran Bandwidth internet Dinas Komunikasi dan Informatik Purwakarta yang berjumlah 43 opd. Data tersebut nantinya akan diproses untuk dapat menghasilkan tingkat kebutuhan bandwidth yang sesuai dengan sistem data mining yang digunakan. Contoh data sebaran yang didapatkan dapat dilihat pada table 1:

Tabel 1. Contoh data sebaran

\begin{tabular}{|c|c|c|c|c|c|c|c|c|c|}
\hline id & $\begin{array}{l}\text { Nama } \\
\text { OPD }\end{array}$ & $\begin{array}{l}\text { Alamat } \\
\text { Lokasi }\end{array}$ & Latitude & Longtitude & $\begin{array}{l}\text { Sebaran } \\
\text { bw }\end{array}$ & $\begin{array}{l}\text { Kapasitas } \\
\text { metro }\end{array}$ & $\begin{array}{l}\text { Alamat } \\
\text { ip }\end{array}$ & $\begin{array}{l}\text { Jumlah } \\
\text { Pengguna }\end{array}$ & $\begin{array}{l}\text { Keteran } \\
\text { gan }\end{array}$ \\
\hline 1 & $\begin{array}{l}\text { Sekertariat } \\
\text { Daerah } \\
\text { Purwakarta }\end{array}$ & $\begin{array}{l}\text { Jl. } \\
\text { Gandanega } \\
\text { ra No.25 }\end{array}$ & $\begin{array}{l}- \\
6.557 .0 \\
02\end{array}$ & $\begin{array}{l}107.442 .2 \\
70\end{array}$ & 20 & 20 & & 10 & - \\
\hline 2 & $\begin{array}{l}\text { Sekertariat } \\
\text { DPRD } \\
\text { Purwakarta }\end{array}$ & $\begin{array}{l}\text { Jalan } \\
\text { Pemuda } \\
\text { Blok Haji } \\
\text { Makbul } \\
\text { No. 26, }\end{array}$ & $\begin{array}{l}- \\
6.564 .4 \\
71\end{array}$ & $\begin{array}{l}107.432 .7 \\
53\end{array}$ & 6 & 6 & & 3 & - \\
\hline 3 & $\begin{array}{l}\text { Inspektorat } \\
\text { Daerah } \\
\text { Purwakarta }\end{array}$ & $\begin{array}{l}\text { Jl. Veteran } \\
\text { No.147, }\end{array}$ & $\begin{array}{l}- \\
6.527 .8 \\
71 \\
\end{array}$ & $\begin{array}{l}107.446 .8 \\
52\end{array}$ & 6 & 6 & & 3 & - \\
\hline 4 & $\begin{array}{l}\text { Dinas } \\
\text { Pendidikan } \\
\text { Purawakarta }\end{array}$ & $\begin{array}{l}\text { Jl. } \\
\text { Surawinata } \\
\text { No.30A, }\end{array}$ & $\begin{array}{l}- \\
6.545 .8 \\
82\end{array}$ & $\begin{array}{l}107.445 .5 \\
13\end{array}$ & 7 & 10 & & 5 & - \\
\hline
\end{tabular}

\section{B. Explore}

Setelah melakukan pengumpulan data dilakukanlah penyeleksian atribut kepada data awal yang didapatkan, penyeleksian ini bertujuan untuk memilih dan memilah atribut apa saja yang harus diambil atau dibuang. Adapun teknik yang penulis gunakan dalam seleksi data ini yaitu feature selection yang terdiri dari tahap Eliminate, engineer, dan validate [6].

1. Eliminate
Pada tahap ini penulis melakukan pemilihan atribut yang akan digunakan seperti id, nama OPD, Latitude, Longtitude, sebaran_bw, kapasitas metro, dan jumlah pengguna.

2. Engineer

Setelah proses eliminate selanjutnya data sumber tersebut dibentuk kembali menjadi data yang siap divalidasi . Hasil dari tahap engineer dapat dilihat pada table 2

Tabel 2. Pengolahan Data

\begin{tabular}{|c|c|c|c|c|c|c|}
\hline id & Nama OPD & Latitude & Longtitude & Sebaran bw & Kap. metro & Jumlah pengguna \\
\hline 1 & $\begin{array}{l}\text { Sekertariat Daerah } \\
\text { Purwakarta }\end{array}$ & $\begin{array}{l}- \\
6.557 .002\end{array}$ & 107.442 .270 & 20 & 20 & 10 \\
\hline 2 & Sekertariat DPRD & - & 107.432 .753 & 6 & 6 & 3 \\
\hline
\end{tabular}




\begin{tabular}{lllllll}
\hline & Purwakarta & 6.564 .471 & & & & \\
\hline 3 & $\begin{array}{l}\text { Inspektorat Daerah } \\
\text { Purwakarta }\end{array}$ & $\begin{array}{l}6.527 .871 \\
4\end{array}$ & 107.446 .852 & 6 & 6 & 3 \\
\hline $\begin{array}{l}\text { Dinas Pendidikan } \\
\text { Purawakarta }\end{array}$ & -6.545 .882 & 107.445 .513 & 10 & 10 & 5 \\
\hline
\end{tabular}

\section{Modify}

Tahap ini melakukan modifikasi terhadap data dengan menciptakan, memilih, dan mengubah variable untuk focus pada proses pemilihan model. Pada tahap ini atribut yang asalnya Numeric menjadi tipe kategori dengan tujuan untuk memudahkan dalam pemrosesan data mining [7]. Dan atribut yang dikelompokan dan dinisialisasi adalah atribut Jumlah Pengguna. Untuk hasil pengelompokan atribut Jumlah Pengguna dapat dilihat pada Tabel 3.

Tabel 3. Transformasi Numeric menjadi kategori

\begin{tabular}{ccc}
\hline No & Jml_pengguna & Inisialisasi \\
\hline 1 & $1-5$ & Rendah \\
\hline 2 & $6-10$ & Sedang \\
\hline 3 & $11-15$ & Tinggi
\end{tabular}

Selain Jumlah Pengguna penulis juga mengubah data koordinat kedalam bentuk pemetaan maps sesuai dengan data koordinat latitude dan longitude. Untuk hasil transformasi data koordinat dapat dilihat pada gambar 2.

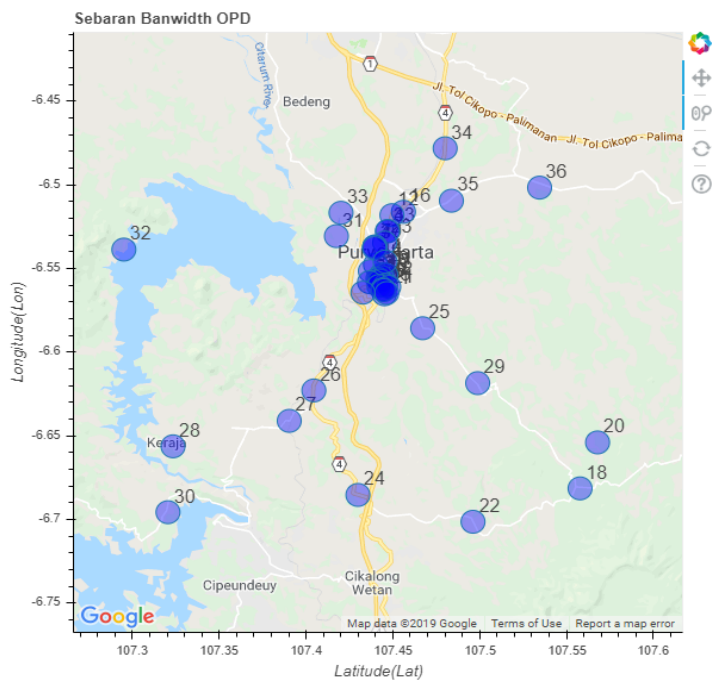

Gambar 2. Transformasi Data ke Map

Untuk hasil keseluruhan dari proses transformasi dapat dilihat pada tabel 3.6 yang menjelaskan rincian dari pemetaan pada map

Tabel 3. Transformasi Tabel dari map

\begin{tabular}{lllllll}
\hline id & Nama OPD & Latitude & Longtitude & Sebaran bw & Kap. metro & Jumlah pengguna \\
\hline 1 & $\begin{array}{l}\text { Sekertariat Daerah } \\
\text { Purwakarta }\end{array}$ & $\begin{array}{l}- \\
6.557 .002\end{array}$ & 107.442 .270 & 20 & 20 & 2 \\
\hline 2 & $\begin{array}{l}\text { Sekertariat DPRD } \\
\text { Purwakarta }\end{array}$ & $\begin{array}{l}- \\
6.564 .471\end{array}$ & 107.432 .753 & 6 & 6 & 1 \\
\hline 3 & $\begin{array}{l}\text { Inspektorat Daerah } \\
\text { Purwakarta }\end{array}$ & $\begin{array}{l}- \\
6.527 .871\end{array}$ & 107.446 .852 & 6 & 6 & 1 \\
\hline 4 & $\begin{array}{l}\text { Dinas Pendidikan } \\
\text { Purawakarta }\end{array}$ & $\begin{array}{l}- \\
6.545 .882\end{array}$ & 107.445 .513 & 10 & 10 & 1 \\
\hline
\end{tabular}




\section{Model Analisis menggunakan Algoritma DBSCAN}

Analisa perhitungan algoritma DBSCAN menggunakan 43 data organisasi perangkat daerah yang ada di purwakarta, untuk perhitungan manualnya dapat dilihat dari iterasi yang dibuat.

Iterasi 1 adalah dengan mengitung jarak masing masing point atau titik terhadap titik pusat 2. Berikut adalah perhitungan jarak masing-masing titik dengan core point untuk iterasi pertama, pada soal diatas dengan menggunakan rumus jarak [8].

a. MinPts : 5

b. Eps : 3

c. Pusat Titik 2 Latitude $=107,432753$

Longitude $=-6,564471$ Sebaran $=6$;

Kapasitas $=6$ pengguna $=1$.

$$
\sqrt{(-6,564471-6,564471)^{2}+} \begin{gathered}
(107,432753-107,432753)^{2} \\
+(6-6)^{2}+(6-6)^{2}+(1-1)^{2}=0
\end{gathered}
$$

\section{E. Analisis Data Mining}

Berdasarkan hasil yang didapatkan dari visualisasi, didapatkan sebuah pengetahuan sebagai berikut :

1. Total cluster pada sebaran bandwidth internet organisasi perangkat daerah yang terbentuk adalah 2 dengan total Noise sebanyak 7 dari 43 data sebaran bandwidth yang diolah dengan menggunakan algoritma DBSCAN

2. Untuk cluster 1 terdiri dari 15 organisasi perangkat daerah, untuk hasil pengelompokkan dapat dilihat pada tabel 4:

\section{Tabel 4. Data OPD Cluster 1}

\begin{tabular}{llc}
\hline No & Nama OPD & Cluster \\
\hline 1 & Sekertariat DPRD Purwakarta & 1 \\
\hline 2 & $\begin{array}{l}\text { Inspektorat Daerah } \\
\text { Purwakarta }\end{array}$ & 1 \\
\hline 3 & Dinas PU Bina Marga dan & 1
\end{tabular}

\begin{tabular}{|c|c|c|}
\hline & Pengairan Purwakarta & \\
\hline 4 & $\begin{array}{l}\text { Dinas Tata Ruang dan } \\
\text { Permukiman }\end{array}$ & 1 \\
\hline 5 & $\begin{array}{l}\text { Dinas Sosial Pemberdayaan } \\
\text { Perempuan Dan } \\
\text { Perlindungan Anak } \\
\text { Purwakarta }\end{array}$ & 1 \\
\hline 6 & Dinas Polisi Pamong Praja & 1 \\
\hline 7 & $\begin{array}{l}\text { Dinas Pemadam Kebakaran } \\
\text { dan Penanggulangan } \\
\text { Bencana }\end{array}$ & 1 \\
\hline 8 & $\begin{array}{l}\text { Dinas Pemberdayaan } \\
\text { Masyarakat Dan Desa }\end{array}$ & 1 \\
\hline 9 & $\begin{array}{l}\text { Dinas Perhubungan } \\
\text { Kabupaten Purwakarta }\end{array}$ & 1 \\
\hline 10 & $\begin{array}{l}\text { Dinas Koperasi UKM, } \\
\text { Perdagangan, dan } \\
\text { Perindustrian }\end{array}$ & 1 \\
\hline 11 & $\begin{array}{l}\text { Dinas Pemuda Olahraga } \\
\text { Pariwisata Dan Kebudayaan }\end{array}$ & 1 \\
\hline 12 & $\begin{array}{l}\text { Dinas Kearsipan dan } \\
\text { Perpustakaan }\end{array}$ & 1 \\
\hline 13 & $\begin{array}{l}\text { Badan Lingkungan Hidup } \\
\text { Purwakarta }\end{array}$ & 1 \\
\hline 14 & Kecamatan Cibatu & 1 \\
\hline 15 & Radio Pro 89 FM & 1 \\
\hline
\end{tabular}

Untuk cluster 2 terdiri dari 21 organisasi perangkat daerah, untuk hasil pengelompokkan dapat dilihat pada tabel 5 :

Tabel 5. Data OPD Cluster 2

\begin{tabular}{clc}
\hline No & Nama OPD & Cluster \\
\hline 1 & Kecamatan Wanayasa & 2 \\
\hline 2 & Kecamatan Kiarapedes & 2 \\
\hline 3 & Kecamatan Bojong & 2 \\
\hline 4 & $\begin{array}{l}\text { Kantor Kecamatan } \\
\text { Purwakarta }\end{array}$ & 2 \\
\hline 5 & Kecamatan Darangdan & 2 \\
\hline 6 & $\begin{array}{l}\text { Kecamatan Pasawahan } \\
\text { Purwakarta }\end{array}$ & 2 \\
\hline 7 & Kecamatan Sukatani & 2 \\
\hline 8 & Kecamatan Plered & 2 \\
\hline 9 & Kecamatan Tegalwaru & 2 \\
\hline 10 & Kecamatan Pondok Salam & 2
\end{tabular}




\begin{tabular}{lll}
\hline 11 & Kecamatan Maniis & 2 \\
\hline 12 & Kecamatan Jatiluhur & 2 \\
\hline 13 & Kecamatan Sukasari & 2 \\
\hline 14 & Kecamatan Babakancikao & 2 \\
\hline 15 & Kecamatan Bungursari & 2 \\
\hline 16 & Kecamatan Campaka & 2 \\
\hline 17 & Kelurahan Purwamekar & 2 \\
\hline 18 & Kelurahan Cipaisan & 2 \\
\hline 19 & Kelurahan Sindangkasih & 2 \\
\hline 20 & Puskesmas Kota Purwakarta & 2 \\
\hline 21 & Kantor Kesbangpol & 2
\end{tabular}

Untuk Noise terdiri dari 7 organisasi perangkat daerah, untuk hasil pengelompokkan dapat dilihat pada tabel 6 :

Tabel 6. Data yang masuk Noise

\begin{tabular}{clc}
\hline No & Nama OPD & Ket \\
\hline 1 & $\begin{array}{l}\text { Sekertariat Daerah } \\
\text { Purwakarta }\end{array}$ & Noise \\
\hline 2 & $\begin{array}{l}\text { Dinas Pendidikan } \\
\text { Purawakarta }\end{array}$ & Noise \\
\hline 3 & $\begin{array}{l}\text { Dinas Kependudukan dan } \\
\text { Pencatatan Sipil }\end{array}$ & Noise \\
\hline 4 & $\begin{array}{l}\text { Dinas Komunikasi dan } \\
\text { Informatika }\end{array}$ & Noise \\
\hline 5 & $\begin{array}{l}\text { Dinas Perencanaan } \\
\text { Pembangunan,Penelitian dan } \\
\end{array}$ & Noise \\
\hline 6 & $\begin{array}{l}\text { Badan Keuangan dan Aset } \\
\text { Daerah }\end{array}$ & Noise \\
\hline 7 & LPSE Kabupaten Purwakarta & Noise \\
\hline
\end{tabular}

\section{F. Visualisasi Hasil Data Mining}

Penggalian data pada rapidminer dilakukan dengan mengimport data excel yang sudah disiapkan ke dalam rapidminer, setelah data dimasukan pada read excel kemudian dihubungkan dengan operator modeling Density Based Spatial Clustering with Noise dengan nilai epsilon 3 dan minpoint 5 . Pemodelan cluster dapat dilihat pad gambar 3.
Gambar 3. Alur Pemodelan Cluster Pada Rapidminer

Kemudian hubungankan operator model clustering ke res dengan cara menarik garis dari clu(cluster) uke res. Setelah semua nilai ditentukan maka Algoritma DBSCAN dapat bekerja. Untuk hasil visualisasi dari Clustering algoritma DBSCAN dapat dilihat pada gambar 4 :

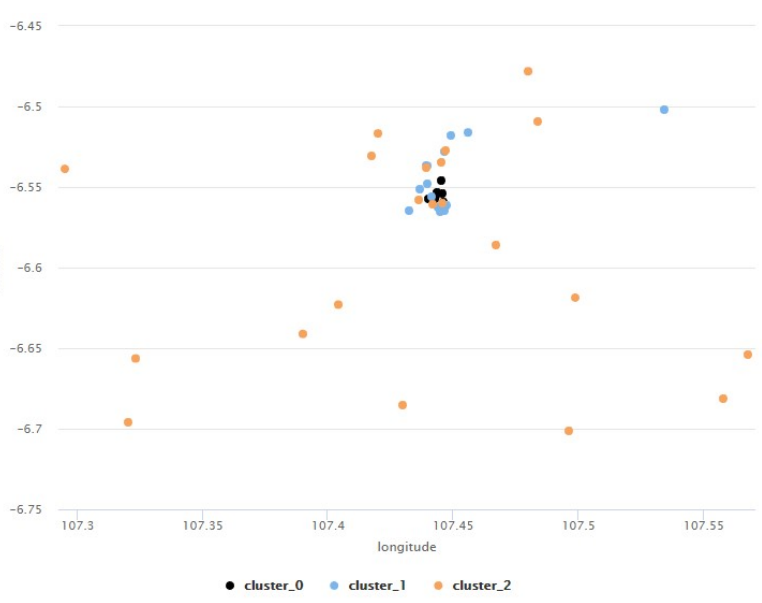

Gambar 4. Ploting Hasil DBSCAN Menggunakan Rapidminer

\section{G. Assess}

Berdasarkan Hasil Analisa algoritma Density Based Spatial Clustering of Application With Noise dengan menggunakan nilai minpts $=5$ dan nilai epsilon $=3$ cluster yang terbentuk yaitu :

1. Cluster 1 terdapat 15 organisasi perangkat daerah

2. Cluster 2 terdapat 21 organisasi perangkat daerah 
3. Noise terdapat 7 organisasi perangkat daerah

Hasil pembagian cluster dari RapidMiner sama dengan perhitungan manual yang dilakukan di Microsoft excel sehingga data yang digunakan valid, dari perhitungan yang sudah dilakukan dapat disimpulkan bahwa cluster 1 yaitu cluster dengan tingkat kebutuhan bandwidth rendah, cluster 2 memiliki tingkat kebutuhan sedang dan Noise itu merupakan kebutuhan bandwidth yang terlalu tinggi, sehingga belum adanya pemerataan pembagian bandwidth di organisasi perangkat daerah Purwakarta [9]. Statistik data cluster yang terbentuk dapat dilihat pada gambar 5 .

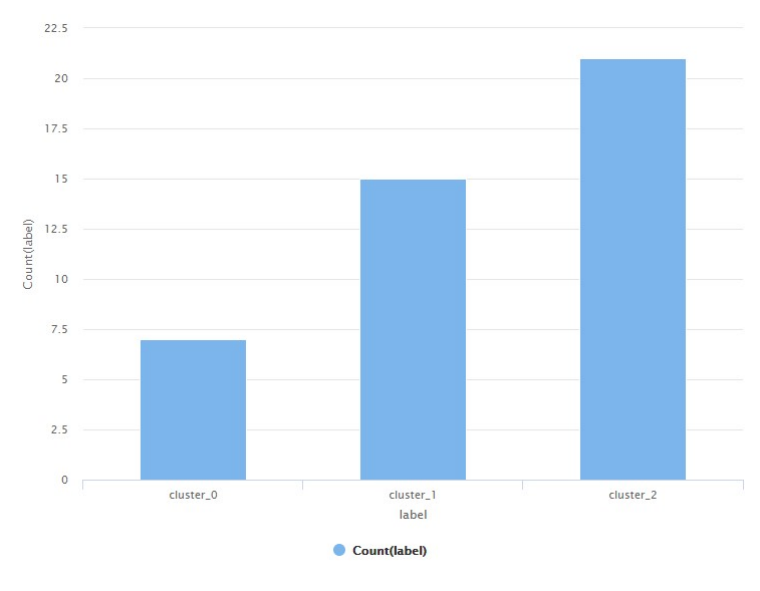

Gambar 5. Statistik Data Cluster Yang Terbentuk

Kesimpulan dari hasil Assess/Evaluasi diatas dapat dilihat sebagai berikut :

1. Cluster 1 dengan tingkat kebutuhan bandwidth rendah berkisar 2 sampai 5 MBps dan perlu ditambahkan kecepatan agar bias dilakukan pemerataan pada sebaran bandwidth.

2. Cluster 2 dengan tingkat kebutuhan sedang berkisar 6 sampai 9 MBps dan sudah memenuhi kriteria standar Bandwidth yang dibagikan.

3. Noise dengan tingkat kebutuhan bandwidth yang tinggi dikarenakan ada beberapa organisasi perangkat daerah purwakarta yang memiliki kebutuhan yang sangat tinggi.

Dari ketiga cluster yang terbentuk perlu dilakukan pemerataan bandwidth agar tidak ada organisasi perangkat daerah yang mendapatkan sebaran bandwidth yang terlalu tinggi dan terlalu rendah [10]. Hasil dari proses clustering ini dapat memberikan kontribusi untuk pemerintah kabupaten Purwakarta dalam melakukan pemerataan sebaran bandwidth pada masing-masing organisasi perangkat daerah.

\section{KESIMPULAN}

Kesimpulan yang didapatkan dari analisis data mining ini adalah pemilihan parameter minpts dan epsilon sangat berpengaruh dalam peroses pengolahan data menggunakan algoritma Density Based Spatial Clustering of Application With Noise. dengan menentukan minpts dan epsilon dapat mempengaruhi proses kerja algoritma untuk menentukan jumlah cluster dan noise yang terbentuk. Hasil cluster menunjukan perbedaan kebutuhan bandwidth pada masing-masing perangkat daerah sehingga dapat dilakukan pemerataan bandwidth yang lebih optimal.

\section{DAFTAR PUSTAKA}

[1] Sander, J., Ester, M., Kriegel, H.-P., \& Xu, X. (1998). Density-based clustering in spatial databases: The algorithm GDBSCAN and its applications. Int. Journal, Kluwer Academic Publishers.

[2] Turban, E., Aronson, J. ., Liang, T. -., \& McCarthy, T. -. (2006). Decision Support Systems, Pearson Education. Decision Support Systems, Pearson Education.

[3] Larose, D. T. (2005). Discovering Knowledge in Data: An Introduction to Data Mining. New Jersey: John Wiley \& Sons, Inc.

[4] Azevedo, Santos, A., \& F, M. (2008). KDD, SEMMA AND CRISP-DM: A PARALLEL OVERVIEW. IADIS. 
[5] Nagpal, P.., \& Mann, P. . (2011). Comparative study if density of based clustering algorithms. American Jurnal of Applications

[6] Prasetyo, E. (2012). Data Mining Konsep dan Aplikasi Menggunakan Matlab. Yogyakarta: ANDI

[7] Arsih, N., Hajarisman, N., \& Darwis, S. (n.d.). Metode Pengclusteran Berbasis Densitas Menggunakan Algoritma DBSCAN. Bandung: Prodi Statistika, Fakultas Matematika dan Ilmu Pengetahuan Alam, Universitas Islam Bandung.

[8] Anindya Santika Devi, N.M., Gede Darma Putra, I.K. dan Sukarsa, I.M., 2015. Implementasi Metode Clustering DBSCAN pada Proses Pengambilan Keputusan. Lontar Komputer, 6(3), pp.185-191

[9] Imanuel Ndaumanu, R., Kusrini dan Arief, M.R., 2014. Analisis Prediksi Tingkat Pengunduran Diri Mahasiswa dengan Metode K-Nearest Neighbor. Jatisi, 1(1).

[10] Kusumo, D.S., Bijaksana, M.A. and Darmantoro, D., 2016. DATA MINING DENGAN ALGORITMA APRIORI PADA RDBMS ORACLE. TEKTRIKA Jurnal Penelitian dan Pengembangan Telekomunikasi, Kendali, Komputer, Elektrik, dan Elektronika, 8(1), pp.1-5 